Original Article

\title{
Standard Precautions among HealthCare Workers in a Tertiary Health Facility in Enugu Metropolis, South-East Nigeria
}

\author{
Hope Nwoga ${ }^{1^{*}}$, Miriam Ajuba ${ }^{1,2}$, Onyinye Chime ${ }^{1,2}$ \\ ${ }^{1}$ Department of Community Medicine, Enugu State University Teaching Hospital Parklane, Enugu, Nigeria \\ ${ }^{2}$ Department of Community Medicine, Enugu State University of Science and Technology College of Medicine, Enugu, \\ Nigeria.
}

*Corresponding Author: Hope Nwoga. Department of Community Medicine, Enugu State University Teaching Hospital Parklane, Enugu, Nigeria. Email: nwogahope@gmail.com.

\begin{abstract}
Background

The work environment of Health Care Workers (HCWs) can be described as a potential risk zone due to numerous hazards endemic to the environment. The hospital is not just only a place where the sick people recover from their illness, but also where the healthy get infected.

\section{Objectives}

To assess the knowledge, attitude and practice of Standard Precautions (SP) among HCWs in a tertiary government health facility in Enugu Metropolis, Nigeria.

\section{Methods}

A descriptive cross-sectional design that used mixed method approach. Qualitative data was collected using an in-depth interview. The quantitative data instrument was a semi-structured, self-administered questionnaire. Manual content analysis was done for the qualitative data. Quantitative data was analysed using SPSS version 22.

\section{Results}

Sixty-four (32.0\%), 131(65.5\%) and 5(2.5\%) had good, fair and poor knowledge of SP respectively while $117(58.5 \%), 70(35.0 \%)$ and $13(6.5 \%)$ had good, fair and poor attitude to SP respectively. Fifty-nine $(29.5 \%), 140(70.0 \%)$ and $1(0.5 \%)$ had good, fair and poor practice of SP respectively.

\section{Conclusion}

There was fair knowledge and practice of SP among the studied HCWs while attitude was good.
\end{abstract}

Rwanda J Med Health Sci 2021;4(3):366-378

Keywords: Standard Precautions, Enugu Metropolis, Healthcare Workers, tertiary health facility

\section{Introduction}

The hospital is not just only a place where the sick people recover from their illness, but also where the healthy get infected.[1] Worldwide, infection has been noted as a major problem in health care settings.[1] The high morbidity and mortality associated with blood borne infections especially in developing countries have remained a major issue worldwide.[2] Occupational exposure to the body fluids can result from percutaneous injury or sharps injury, mucocutaneous injury (splash of blood or other body fluids into the eyes, nose or mouth) or contact with non-intact skin.[3]
This can cause substantial health consequences and psychological stress for HCWs and their loved ones. [4]The concept of Standard Precautions (SP) was proposed by the Centre for Disease Prevention and Control (CDC) in 1996. The aim was to protect both the HCW from being infected and the uninfected patient from getting infected by the HCW.[5] It combined the major features of Universal Precautions (UPs) and Body Substance Isolation (BSI). Universal Precautions (UP) was defined by CDC as a set of precautionary measures designed to prevent transmission of HIV, HBV and other blood borne pathogens when providing first aid or healthcare services. [5,6] 
Standard Precautions apply to all body fluids including blood, secretions and excretions (except sweat) regardless of whether or not they contain visible blood, skin that is not intact, mucous membranes, any unfixed tissue or organ (other than intact skin) from human (living or dead), HIV or HBV containing culture media or other solutions.[7] The infection control problems that emerge during outbreak investigations often indicate the need for new recommendations or reinforcement of existing infection control recommendations to protect patients and HCWs. [7] HCW s should assume that every person is potentially infected or colonized with an organism that could be transmitted in the health care setting and therefore, should apply infection control practices while delivering health care.[7]

There are 9 main components of SP that are recommended and they include hand washing, use of protective barriers to prevent direct contacts, safe handling and disposal of sharps, safe decontamination of instruments and other contaminated equipments, environmental control, patient placement, patient resuscitation, cough etiquette and decontamination of soiled patient linens.[7] The hands have been reported to be the most common vehicle for microbial transmission, therefore hand washing reduces the number of potential infectious agents on the hands. It is also an important means of reducing the incidence of infectious agents in healthcare facilities.[8]The use of Personal Protective Equipment's (PPEs) reduces the HCWs risk of exposure to blood and body fluid by creating a physical barrier. Such protective barriers include (gloves, gown, cap, mask, protective eye wears, and face shields).[9]

Environmental control involves surface processing protocols and health waste handling and cleaning.[9] This protocol involves the routine cleaning of bed, bed railings, patient examination tables and bedside tables with the assumption that they are contaminated.

Respiratory hygiene and cough etiquette involves covering the mouth and nose when coughing or sneezing, hand hygiene after contact with respiratory secretions and spatial separation of persons with acute febrile respiratory symptoms. In setting of Viral Haemorrhagic Fever, N95 or P3 respirator should be necessary.[9] Research has indicated that sharp injury may be under reported by $39.4 \%$ to $75 \%$.[4] Some HCWs are not concerned about infection by sharp injury and forget to report accidents.[4]
The World Health Organization (WHO) defined safe injection as an injection that does not harm the recipient, does not expose the provider to any avoidable risks and does not result in waste that is dangerous for the community.[10]

Injections are one of the most common healthcare procedures and each year about 20 billion injections are administered worldwide.[11] The recipients and HCWs are at risk of infection through contaminated needles and syringes and the community at large through exposure to contaminated sharps. Most injections (95\%) are given for therapeutic purposes, $3 \%$ immunization injections, $1 \%$ injectable contraception and $1 \%$ for blood procedures. It was estimated that each person in developing country receive an average of 3.4 injections per year. In 14 out of 19 countries in five developing world regions with data, 70$90 \%$ of these injections are unnecessary, while at least $50 \%$ are unsafe.[12]

Needle Stick Injuries account for more than 18,000 new cases of hepatitis annually worldwide and in Nigeria the preliminary treatment cost for a single NSI incident is estimated to be between 65,000 and 390,000 Nigerian Naira. [13] Reporting of NSIs by the HCW is also poor making records on the incidence not available. Also the Post Exposure Prophylaxis (PEP) is not well instituted in the country and majority of the workers are not vaccinated against HBV infection.[13]

In most developing countries including Nigeria there has been much concern about knowledge and adherence to SP by HCWs. Most HCWs do not have knowledge about SP and that makes it difficult for them to adhere to it. A study conducted in Lagos, Western Nigeria observed that lack of compliance to SP was primarily due to lack of knowledge.[6] This study highlights a need to implement a programme to improve knowledge of SP to prevent occupational accidents.

Also a study done in Northern Nigeria among HCWs in a tertiary health institution showed that some HCWs do not recognize vaccination (19.2\%), PEP (19.2\%), and surveillance for emerging disease $(28 \%)$ as SP for infection control. [14] It is this widespread lack in knowledge that is partly responsible for the poor attitude and adherence to SP and the consequent high rate of occupational accidents in Nigeria. A similar study among HCWs in North-west Ethiopia also reported that only $32.4 \%$ of the HCWs protect themselves regardless of the patient's diagnosis. [15] 
Further indicating poor knowledge and hence poor practice of SP. Additionally, there was an increasing number of HCWs that present in the Anti-Retroviral Therapy (ART) clinics to assess post-exposure prophylaxis with complaints of needle stick and sharps injuries, Based on this widespread poor knowledge and practice of SP and increase in cases of needle stick and sharp injuries this study was aimed to determine the knowledge, attitude and practice of SP among HCWs in a tertiary health facility in Enugu Metropolis, South-East Nigeria. To the best of our knowledge, no such study has been conducted in this health facility, necessitating our present study.

\section{Methods}

\section{Study setting and design}

This descriptive cross-sectional study was conducted at Enugu State University Teaching Hospital Parklane, Enugu State South East Nigeria which is situated within the Enugu Metropolis. The hospital provides tertiary health care to inhabitants of the state and its environs.

\section{Study population}

The population for this study were all the HCWs (Medical Doctors, nurses/Community Health Extension Workers (CHEWs), laboratory scientists/technicians, ward orderlies) in the study facility directly involved in patient care

\section{Sample size determination}

The minimum sample size for the study was determined using Fisher's statistical formula. [16] It was based on the expected proportion of HCWs that have good practice of SP in tertiary health facility, $74.6 \%$ (from a previous study). [17] Two hundred eligible HCWs were used for the study.

\section{Sampling technique}

A sampling frame consisting of the list of all the HCWs directly involved in patient care obtained from the Administrative Department of the hospital was used. There were about 215 medical doctors, 281 nurses/nurse assistants, 38 laboratory workers and 87 orderlies giving a total of 621 HCWs directly involved in patient care. The HCWs have been naturally stratified based on cadre i.e., Medical doctors, Nurses, Laboratory Scientists, Laboratory Technicians, Nurse Assistants/Community Health Extension Workers, and Ward Orderlies. Proportionate allocation was used to get the number of HCWs for each stratum. In each stratum, systematic sampling technique was used to select the respondents for the study.

\section{Data collection}

The data collection lasted for 4 weeks; 2nd -30th March 2018. The quantitative data was collected with semi-structured pre tested selfadministered questionnaire which was based on the guidelines for Isolation Precautions in hospitals[18]while the qualitative data was collected with an In-Depth Interview (IDI) guide formulated after extensive literature review and according to WHO and CDC guidelines. [19,20] Twenty IDI (10\%) of the sample size, was conducted by the principal investigator assisted by research assistants. Proportionate allocation based on the different cadres of HCWs, was used to select the respondents ( 5 medical doctors, 10 nurses, 2 laboratory workers and 3 orderlies) for the interview. The IDI had 3 sections; knowledge, attitude and practice of SP.

\section{Data management}

\section{Measurement of variables}

The questionnaire was divided into 4 parts. Part 1 was on socio-demographic characteristics, part 2 contained 20 questions on knowledge of basic contents and concepts of SP with 3 possible answers of 'yes', 'no' and 'uncertain'. A correct answer was scored 1 while a wrong one was scored 0 . The maximum score was 20 while the minimum score was 0 . The respondents' knowledge was graded as poor, fair and good based on their score. A score of $0-9$ ( 0 to $<50 \%)$ was graded as poor; $10-18(50 \%$ to $<90 \%)$ was graded as fair while $19-20$ (90\% to $100 \%)$ was graded as good. Part 3 used 12 questions to ascertain the HCWs attitude towards SP. A Likert Scale range of 1-5 was used, with $1=$ strongly disagree, $2=$ disagree, $3=$ neutral, $4=$ agree, $5=$ strongly agree and a minimum score of 12 and maximum score of 60 . Scores of between 12 and $29(<50 \%)$ were graded as poor; $30-53(50 \%$ to $<90 \%)$ as fair while scores of between 54 and 60 (90\% to 100\%) were graded as good. In the fourth part 25 questions were used to determine the respondents' practice of Standard Precautions. A Likert Scale range of 1-4 was used, with $1=$ never, $2=$ rarely, $3=$ sometimes, $4=$ always and a minimum score of 25 and a maximum score of 100. Practice scores of $25-49(<50 \%)$ were graded as poor; $50-$ $89(50 \%$ to $<90 \%)$ as fair while scores of $90-100$ (90\% to $100 \%)$ were graded as good.

\section{Data analysis}

Quantitative data was analyzed using SPSS version 22. The categorical variables were displayed as frequencies and percentages while the continuous variables were displayed as means and with standard deviations. 
Responses of strongly disagree, disagree and neutral on the Likert scale were reported as "NO", while responses of agree and strongly agree were reported as "YES". Manual content analysis was used to analyze the qualitative data.

\section{Results}

Quantitative data results

Table 1. Socio-demographic characteristics of the respondents

\section{Ethical clearance}

Ethical approval to carry out the study was obtained from the Enugu State University Teaching Hospital Ethics Committee. Written informed consent was also obtained from respondents. There was no form of coercion and participation was completely voluntary.

\section{Variable
Age of respondents}

Mean \pm SD(years)

Age in groups

$$
\begin{aligned}
& <30 \text { years } \\
& 30-39 \text { years } \\
& 40-49 \text { years } \\
& >49 \text { years }
\end{aligned}
$$

\section{Gender}

Male

Female

\section{Religion}

Christianity

Islam

\section{Ethnicity}

Igbo

Others

\section{Marital Status}

Single

Married

\section{Educational Level}

Primary/secondary completed

Tertiary

\section{Years of service}

Mean \pm SD

\section{Years of service in groups}

$1-5$

$6-10$

$11-15$

$\geq 16$

\section{Occupation}

Medical Doctor

Nurse/CHEW

Laboratory Scientist/technician

Orderly

\section{Frequency Percentage}

$34.59 \pm 7.7$

$\begin{array}{ll}48 & 24.0 \\ 103 & 51.5 \\ 42 & 21.0 \\ 7 & 3.5\end{array}$

64

32.0

136

68.0

199

99.5

1

0.5

197

98.5

3

1.5

65

32.5

135

67.5

27

173

86.5

$7.68 \pm 5.8$

85

42.5

75

37.5

23

11.5

17

8.5

62

31.0

92

46.0

15

7.5

31

15.5 
A total of $200 \mathrm{HCWs}$ made up of $62(31.0 \%)$ medical doctors, 92 (46.0\%) nurses, 15 (7.5\%) laboratory scientists / technicians and 31(15.5\%) orderlies participated in the study. Table 1 shows the socio-demographic characteristics of the respondents.
The mean age in years of the respondents was 34.59 \pm 7.7 with about half of the HCWs in the age group 30-39 years while the least proportion was $>49$ years. The females, married and those with tertiary education were in the majority with 136 (68.0\%), $135(67.5 \%)$ and $173(86.5 \%)$ respectively. The mean number of years of service was $7.68 \pm 5.8$.

Table 2. Knowledge of Standard Precautions among HealthCare Workers in tertiary government health facility in Enugu Metropolis

\begin{tabular}{|c|c|c|}
\hline \multirow[t]{2}{*}{ Variable } & Yes & No \\
\hline & $\mathbf{N}(\%)$ & $\mathbf{N}(\%)$ \\
\hline Have heard of the term SPs & 195(97.5) & $5(2.5)$ \\
\hline \multicolumn{3}{|l|}{ Source(s) of information* } \\
\hline Radio & $91(45.5)$ & NA \\
\hline Television & $90(45.0)$ & NA \\
\hline Workshop/Seminars & $128(64.0)$ & NA \\
\hline Journals & $93(46.5)$ & NA \\
\hline Textbooks & $144(72.0)$ & NA \\
\hline From a colleague & $113(56.5)$ & NA \\
\hline School & $125(62.5)$ & NA \\
\hline Internet & $8(4.0)$ & NA \\
\hline Have had any training on SPs & $97(48.5)$ & $103(51.5)$ \\
\hline $\begin{array}{l}\text { SP is only applicable to patients with confirmed diagnosis } \\
\text { of infection }\end{array}$ & $12(6.0)$ & $188(94)$ \\
\hline $\begin{array}{l}\text { The goal of SP is to protect both the patients and the med- } \\
\text { ical staff }\end{array}$ & $190(95.0)$ & $10(5.0)$ \\
\hline $\begin{array}{l}\text { Hands should be washed immediately if there is contact } \\
\text { with BBFs }\end{array}$ & 192(96.0) & $8(4.0)$ \\
\hline Hands should be washed in-between patients & $181(90.5)$ & $19(9.5)$ \\
\hline Hands should be washed after removing gloves & 195(97.5) & $5(2.5)$ \\
\hline $\begin{array}{l}\text { Gloves should be worn in any procedure that might entail } \\
\text { contact with BBFs }\end{array}$ & 194(97.0) & $6(3.0)$ \\
\hline Gloves should be changed if contacting different patients & $195(97.5)$ & $5(2.5)$ \\
\hline $\begin{array}{l}\text { Face mask should be worn in procedures that might in- } \\
\text { duce the spraying of BBF }\end{array}$ & 187(93.5) & $13(6.5)$ \\
\hline $\begin{array}{l}\text { Goggle should be worn when spraying of BBFs is suspect- } \\
\text { ed }\end{array}$ & $191(95.5)$ & $9(4.5)$ \\
\hline $\begin{array}{l}\text { Apron should be worn in procedures that might induce the } \\
\text { spraying of BBFs }\end{array}$ & $191(95.5)$ & $9(4.5)$ \\
\hline $\begin{array}{l}\text { Protective cap or shoe should be worn in procedures that } \\
\text { might induce the spraying, or leaking of BBFs }\end{array}$ & $191(95.5)$ & $9(4.5)$ \\
\hline $\begin{array}{l}\text { Sharp disposable box should be close to sharp applicable } \\
\text { area }\end{array}$ & $191(95.5)$ & $9(4.5)$ \\
\hline \multicolumn{3}{|l|}{ Knowledge categorized } \\
\hline Poor & $5(2.5)$ & NA \\
\hline Fair & $131(65.5)$ & NA \\
\hline Good & $64(32.0)$ & NA \\
\hline
\end{tabular}

BBFs blood and body fluids NA not applicable 
In Table 2, 195 (97.5\%) of the respondents had heard about standard precautions and textbooks was the commonest source of information $144(72.0 \%)$. Other sources include workshops / seminars 128 (64.0\%), school 125 (62.5\%), from colleagues 113 (56.5\%), journals 93 (46.5\%), radio 91 (45.5\%), television $90(45.0 \%)$ and internet 8 (4.0\%). Ninety-seven (48.5\%) had had some training on SPs. One hundred and eighty-eight $(94.0 \%)$ of the respondents knew that SPs is applied to all patients irrespective of their diagnosis. One hundred and ninety $(95.0 \%)$ knew that the goal of SP is to protect both the patient and the HCWs.Concerning hand hygiene, majority of the HCWs knew that hands should be washed: immediately if there is contact with blood/body fluids 192 (96.0\%), inbetween patients 181 (90.5\%) and after removal of gloves 195 (97.5\%).
In addition, majority of the HCWs knew that gloves should be worn in procedures that might entail contact with blood/ body fluids 194 $(97.0 \%)$ and should be changed if contacting different patients 195 (97.5\%). Majority of the HCWs also knew that face mask 187 (95.5\%), goggle 191 (95.5\%), apron 191 (95.5\%) and protective cap/shoe 191 (95.5\%) should be worn in procedures that might induce the spraying of blood/body fluids. One hundred and ninety one $(95.5 \%)$ knew that sharp disposable box should be close to sharp applicable area.

Sixty four $(32.0 \%)$ of the HCWs had good knowledge, 131 (65.5.0\%) had fair knowledge while $5(2.5 \%)$ had poor knowledge of SP.

Table 3. Attitude to Standard Precautions among healthcare workers in a tertiary government health facility in Enugu Metropolis

\begin{tabular}{|c|c|c|}
\hline Variable & $\begin{array}{l}\text { Yes } \\
\text { N (\%) }\end{array}$ & $\begin{array}{l}\text { No } \\
\text { N (\%) }\end{array}$ \\
\hline SP can prevent the spread of infectious diseases & $183(91.5)$ & $17(8.5)$ \\
\hline $\begin{array}{l}\text { SP are very important approaches in healthcare } \\
\text { procedures }\end{array}$ & $184(92.0)$ & $16(8.0)$ \\
\hline Can acquire HIV if you don't comply with SP & $180(90.0)$ & $20(10.0)$ \\
\hline Can acquire HBV if you don't comply with SP & $176(88.0)$ & $24(12.0)$ \\
\hline Can acquire HCV if you don't comply with SP & $164(82.0)$ & $36(18.0)$ \\
\hline Needles should not be recapped after use & $120(60.0)$ & $80(40.0)$ \\
\hline $\begin{array}{l}\text { Used needles should be disposed immediately in a } \\
\text { sharp disposable box }\end{array}$ & 183(91.5) & $17(8.5)$ \\
\hline All HCWs should be immunized against HBV & $178(89.0)$ & $22(11.0)$ \\
\hline $\begin{array}{l}\text { PEP should be taken after exposure to } \mathrm{BBF} \text { of } \mathrm{HIV} \\
\text { positive patients }\end{array}$ & $181(90.5)$ & $19(9.5)$ \\
\hline $\begin{array}{l}\text { HBig and HBV vaccine should be taken after exposure to } \\
\text { BBF of Hep B positive patients if HCW is not immunized } \\
\text { against HBV }\end{array}$ & $168(84.0)$ & $32(16.0)$ \\
\hline Health facility should have a clear SP guideline & $182(91.0)$ & $18(9.0)$ \\
\hline $\begin{array}{l}\text { Health facility should have a reporting system for OAs } \\
\text { Attitude categorized }\end{array}$ & $178(89.0)$ & $22(11.0)$ \\
\hline Poor & $13(6.5)$ & NA \\
\hline Fair & $70(35.0)$ & NA \\
\hline Good & $117(58.5)$ & NA \\
\hline
\end{tabular}


Table 3 shows the attitude of HCWs towards SP whereby 183 (91.5\%) of the HCWs believed that SP can prevent the spread of infectious diseases, $184(92.5 \%)$ that SP are quite important approaches in healthcare procedures. Majority of the HCWs agreed that one can acquire HIV 180 (90.5\%), HBV 176 (88.0\%) and HCV 164 $(82.0 \%)$ if they do not comply with SP. One hundred and twenty (60.0\%) and 183 (91.5\%) agreed that needles should not be recapped after use and that used needles should be disposed immediately in a sharp disposable box.
Majority of the HCWs also agreed that all HCWs should be immunized against HBV 178 (89.0\%), that PEP should be taken after exposure to BBF of HIV positive patients 181 (90.5\%) and that HBIg and HBV vaccine should be taken after exposure to BBF of HBV positive patients if HCWs is not immunized against HBV 168 (84.0\%). Furthermore, $182(91.0 \%)$ and $178(89.0 \%)$ agreed that health facilities should have clear SP guidelines and a reporting system for occupational accidents respectively. One hundred and seventeen $(58.5 \%)$ of the HCWs had good attitude towards SP, $70(35.0 \%)$ had fair attitude while $13(6.5 \%)$ had poor attitude towards SP.

Table 4. Practice of Standard Precautions among healthcare workers in a tertiary government health facility in Enugu Metropolis

\begin{tabular}{lll}
\hline Variable & Yes & No \\
& N (\%) & N (\%) \\
\hline Wash hands in between patients & $94(47.0)$ & $106(53.0)$ \\
Wash hands after taking off gloves & $154(77.0)$ & $46(23.0)$ \\
Wash hand immediately after contact with BBF & $179(89.5)$ & $21(10.50$ \\
Wear gloves during disposal of BBFs & $192(96.0)$ & $8(4.0)$ \\
Wear gloves when in contact with impaired skin & $163(81.5)$ & $37(18.5)$ \\
Wear gloves while handling contaminated linen & $166(83.0)$ & $34(17.0)$ \\
Wear gloves when handling refuse/waste & $181(90.5)$ & $19(9.5)$ \\
Wear gloves when in contact with mucosa of patients & $178(89.0)$ & $22(11.0)$ \\
Wear gloves when in contact with saliva of patients & $164(82.0)$ & $36(18.0)$ \\
Wear gloves when giving IM injection & $121(60.5)$ & $79(39.5)$ \\
Wear gloves while changing wound dressing & $193(96.5)$ & $7(3.5)$ \\
Wear gloves while clearing blood trace & $188(94.0)$ & $12(6.0)$ \\
Wear gloves during venous puncture & $188(94.0)$ & $12(6.0)$ \\
Wear gloves when in contact with blood sample & $185(92.5)$ & $15(7.5)$ \\
Wear goggle in procedures that might induce spraying of $133(66.5)$ & $67(33.5)$ \\
BBF & & \\
Wear face mask in procedures that might induce & the $140(70.0)$ & $60(30.0)$ \\
spraying of BBF & & \\
Wear apron in procedures that might induce spraying of $130(65.0)$ & $70(35.0)$ \\
BBF & & \\
Wear protective cap/ shoe shade in procedures that might $107(53.5)$ & $93(46.5)$ \\
induce the spraying of BBF & & \\
Clean and tape up skin if injured by polluted sharp & $161(80.5)$ & $39(19.5)$ \\
Recap needles after use & $139(69.5)$ & $61(30.5)$ \\
Detach needle from syringe after use & $38(19.0)$ & $162(81.0)$ \\
Bend needles after use & $18(9.0)$ & $182(91.0)$ \\
Sterilize and reuse needles / syringes & $13(6.5)$ & $187(93.5)$ \\
Dispose needles/syringes immediately after use in sharp $139(69.5)$ & $61(30.5)$ \\
disposable boxes & & \\
Report NSSI by polluted sharps & $96(48.0)$ & $104(52.0)$ \\
Always compliant with SP practices & $100(50.0)$ & $100(50.0)$ \\
Practice categorized & & \\
Poor & $1(0.5)$ & NA \\
Fair & $140(70.0)$ & NA \\
Good & $59(29.5)$ & NA \\
Practice Dichotomized & $141170.5)$ & NA \\
Poor & $59(29.5)$ & NA \\
Good & & \\
BBF blood and body fluids & NA not applicable & \\
& &
\end{tabular}


Table 4. Responses of "never" and "neutral" on the Likert Scale were reported as "NO" while responses of "sometimes" and "always" were reported as "YES". Regarding practice of SP, hand washing was always practiced by 94 $(47.0 \%)$ of the HCWs in between patients, 154 $(77.0 \%)$ after taking off gloves and 179 (89.5\%) immediately after contact with BBF. Majority of the HCWs always wear hand gloves; during disposal of BBFs 192 (96.0\%), when in contact with impaired skin 163 (81.5\%), while handling contaminated linen $166(83.0 \%)$, when handling refuse/waste 181 (90.5\%), when in contact with mucosa of patients $178(89.0 \%)$, when in contact with saliva of patients $164(82.0 \%)$, while changing wound dressing 193 (96.5\%), while clearing blood trace 188 (94.0\%), during venous puncture $188(94.0 \%)$ and when in contact with blood sample 185 (92.5\%). However, only 121 $(60.5 \%)$ of the HCWs wore gloves when giving IM injection.
The regular use of goggles, face mask, apron and protective cap/shoe in procedures that might induce the spraying of BBF was reported by $133(66.5 \%), 140(70.0 \%), 130(65.0 \%)$ and 107 (53.5\%) of the HCWs respectively.

One hundred and sixty-one (80.5\%) of the HCWs always cleans and tape up skin injured by polluted sharps. Regarding the use of sharps, 139 (69.5\%), 38 (19.0\%), 18 (9.0\%), 13 (6.5\%) and $139(69.5 \%)$ admitted to always: recap needles, detach needles, bend needles, sterilize and reuse needles and dispose needles/syringes immediately in sharp boxes after use. Only 96 $(48.0 \%)$ reported NSSI by polluted sharps. Half of the HCWs $100(50.0 \%)$ reported to always comply with SP.

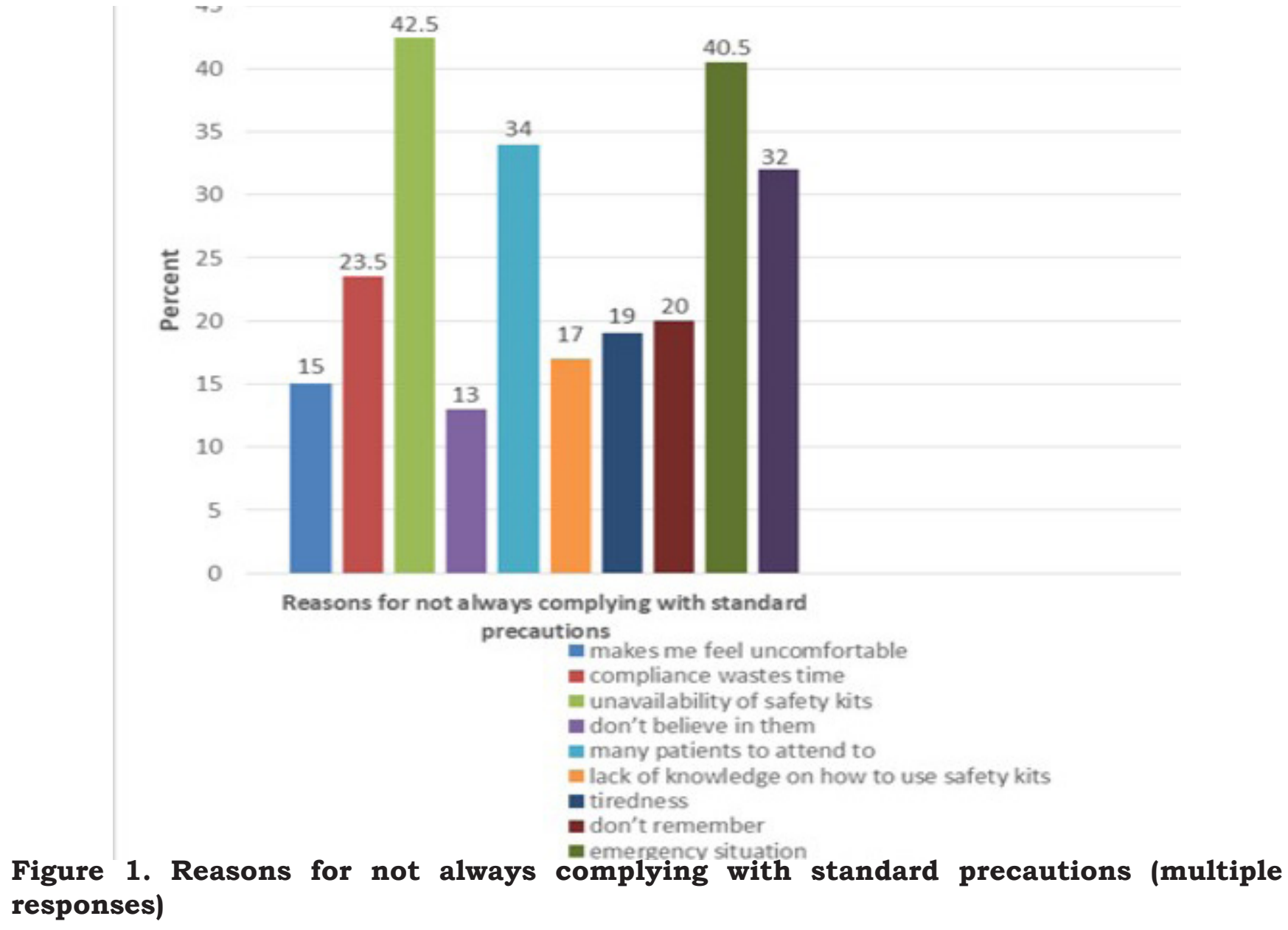


Figure 1 shows that the major reason for noncompliance was unavailability of safety kits 85 $(42.5 \%)$ followed by emergency situations 81 $(40.5 \%)$.

Fifty-nine $(29.5 \%)$ of the HCWs had good practice of SP, $140(70.0 \%)$ had fair practice while $1(0.5 \%)$ had poor practice of SP.

\section{Qualitative data results}

\section{Qualitative data on knowledge of SP}

Most of the HCWs interviewed had good knowledge of SP. They were able to give good explanation of SP. One of the HCWs had this to say,

"SP are all the precautionary measures you take to avoid contacting infections or diseases like HIV and the likes [sic]. It is both for the HCW and the patient" [sic].

They were also able to mention some of the components of SP. A HCW put it thus,

"SP measures include proper washing of hands, wearing of gloves and other PPEs and screening of blood for blood transfusion" [sic].

In contrast to this, some of the HCWs did not have the right knowledge about SP. They also complained of no formal training on SP. Some of them said this,

"SP is a process by which the HCW protect themselves against any infection or disease" [sic] "I only heard about SP from a colleague, so I don't know much about SP" [sic].

\section{Qualitative data on attitude towards SP}

A nurse had this to say on attitude,

"I had needle prick while discarding needle used to puncture intravenous fluid. I think I wasn't too careful" [sic]

Poor attitude to PPE was asserted by a medical doctor, who had this to say,

"Most HCWs do not always have PPE for use but they are also not disciplined to use the available ones" [sic]

\section{Qualitative data on practice of SP}

Majority of those interviewed believe their health facilities do not have the necessary facilities for good practice of SP. A medical doctor graded the practice of SP in the health facility thus, "I will grade this place $30-40 \%$ because the necessary things needed are not provided in this hospital"

A nurse also had this to say,

"...40\%, because this place is not well equipped by the government. . We normally use improvised and minor PPE while doing our work"
A nurse also believed that the practice of SP was much better in her facility due to trainings organized by the hospital management. She had this to say,

"I will grade this place $85 \%$ because most of us are informed about SP and keep to it. They are more informed than before because of training by the hospital committee on infection control"

\section{Discussion}

Majority of the studied HCWs knew that HIV, HBV and HCV are transmitted by NSSIs. Other studies reported similar findings.[21] Majority of the HCWs (94.0\%) knew that SP is applicable to all patients irrespective of their diagnostic status. This finding is comparable to similar studies in Nigeria[22,23] but higher than the findings in United Arab Emirates[24] (61.2\%) and North West Ethiopia[15] where only $32.4 \%$ of the HCWs protected themselves against blood/body fluid exposure regardless of diagnosis of the patient. Also, majority of the HCWs knew that the goal of SP is to protect both the patients and the HCWs. This finding was higher than what was observed in other studies in Nigerian[23] and United Arab Emirates.[24] Majority of the respondents had good knowledge of hand hygiene. Hand hygiene have been described as the most important procedure for reducing infection transmission.[4] Similar studies in Nigeria,[22,23] and Egypt[25] also reported high knowledge of hand hygiene.

Majority of the respondents knew that gloves should be worn during venopuncture, in any procedure that might entail contact with blood/ body fluids and that glove should be changed if contacting different patients. This was not surprising as all the HCWs come in contact with gloves regularly in the course of discharging their duties. High knowledge of glove use was also reported in similar studies. [22] However an Egyptian pre and post study[26] conducted among nurses to assess the effect of a developed educational booklet about SP on nurses knowledge and practice of SP reported poor knowledge of glove use (29.2\%) pre the educational booklet and even after the educational booklet, the knowledge increased to only $44.6 \%$ which is still poor. This is surprising as the study was among nurses that work in the emergency and operating rooms in a tertiary health facility. Majority of the respondents had good knowledge of other PPEs (face mask, goggles, apron, and protective cap) for infection control. Good knowledge of PPE was also reported in a similar study in Nigeria.[17], 
The similarity in the studies may be due to similar educational status of the respondents in the studies. Also, the level of training on SP may be a contributing factor. However a study among nurses in Egypt[25] reported poor knowledge of PPE. Most of the respondents (95.5\%) have good knowledge of sharp disposal and this was reported in similar studies.[17, 25,27] This good knowledge of sharp disposable may be due to the fact that sharp disposal boxes are supplied with the immunization drugs thus increasing its awareness. However another study among nurses[26] reported lower knowledge of sharp disposal (12.3\%) and this was surprising as nurses are supposed to have good knowledge of SP. Thus, the low knowledge in the study can be due to poor awareness and/or training on SP.

This study showed high awareness of SP among the HCWs as majority of them (97.5\%) have heard about SP but the deep knowledge of SP was poor. Only about $32.0 \%$ of respondents had good knowledge of SP. This was comparable to what was reported in a similar study.[24] This calls for more in-depth training to convert the awareness to knowledge.

The IDI also showed that though majority of the HCWs had good knowledge of SPs, there are still some that had not heard about it. Emphasis on such important topic as standard precautions should be incorporated into the training of HCWs at all levels.

More than half of the respondents (58.5\%) had good attitude to SP. This is similar to the result of the IDI as about half of the respondents had good attitude to SP. This finding was however lower than what was reported in another Nigerian study[23] among nurses with attitude score of $86.8 \%$ among the nurses. The difference in attitude score can be explained by the fact that the study used a median score of $>60 \%$ as cut off for good attitude while this study used $90.0 \%$ as cut off for good attitude score. Majority of the HCWs (91.5\%) believe that SP can prevent the spread of infectious diseases and the finding is comparable to the report of a similar study in South East Nigeria.[17] The similarities may be due to comparable cadre and educational level of HCWs in the study groups. Slightly higher than half of the respondents (60.0\%) believe that needles should not be recapped after use. The above findings show poor attitude towards injection practices which is a major component of SP. Poor attitude towards injection practices can lead to poor practice of injection safety which was described as a risk not only to the individual but to the community at large.[11] The finding in this study was however comparable to another similar study in Nigeria (61.0\%). [28]
Majority of the HCWs (91.5\%) believe that used needles should be disposed immediately in a sharp disposable box. High attitude to sharp disposable boxes have also been reported in a similar study in Nigeria.[29]

Also, majority of the HCWs (84.0\%) agree that Hepatitis B immunoglobulin and Hepatitis B vaccine should be taken after exposure to blood/ body fluids of Hepatitis B positive patients if the $\mathrm{HCW}$ is not immunized against HBV. This was comparable to the report of a study in Northern Nigeria[14] where $80.8 \%$ of HCWs believe that PEP is part of SP for infection prevention. This shows a good attitude towards HBV PEP, however the high rate of transmission makes it imperative that all HCWs should have good attitude to HBV PEP. A study done in Southern Nigeria[30] to assess the epidemiology and management of occupational exposure to blood borne viral infections found out that $7.7 \%$ of the studied HCWs sero-converted for HBV after 6 months even though the HCW received PEP for HBV. This calls for more awareness and good attitude towards SP in order to prevent such incidences.

Less than half of the respondents (47.0\%) wash their hands in between patients. Furthefrmore, the direct observation made at the health facilities shows that only about $20.0 \%$ of the observed HCWs washed hands in between patients. The finding was however lower than the findings in a Nigerian study[23] where $82.6 \%$ of the respondents washed hands after patient contact. The higher rate of hand washing may be due to the fact that the health facility is a referral centre for management of Lassa fever and majority of the HCWs are conscious of infection prevention. A multi-centre study in Northern Ethiopia[31] also reported similar finding. Moreover, majority of the respondents washed their hands after taking off gloves and immediately after contact with blood/body fluids. Similar study in Vietnam[32] corroborated with this. However, a study in Bengal India among interns and medical college students reported lower practice of hand washing $(54.7 \%)$. The poor practice may be explained by the fact that they are young in the profession and may not have received formal training on SP. Year of service have been positively correlated with good practice.[33] Generally the practice of hand washing in this study was not optimal since hands are the commonest mode of infection transmission in healthcare settings. Hand washing have also been shown to be the most important procedure for reducing infection transmission[4] and a major component of SP. 
The use of gloves was high among the HCWs. Similar study from Ethiopia reported similar findings.[15] This can be due to the fact that almost all categories of HCWs use gloves at some point as they discharge their duties. The use of other PPEs like goggle, face mask, apron and protective cap/shoe shade was poor as only about half of the HCWs use them always in procedures that might entail the spraying of BBF. This was similar to what was reported in other studies in Nigeria[23], North West Ethiopia[15], Egypt[26] and Kampala. [34] Unavailability of PPE was the major reason for non-adherence to SP in this study. It has been shown that provision of PPE by the health facilities improves practice of SP.[34]

Most of the respondents always recap needles after use. This practice predisposes HCWs to Needle Stick Injuries (NSIs) which can expose them to blood borne pathogens. However other studies in Nigeria, $[22,23,27]$ Ethiopia, $[15,31,36]$ and Uganda[30,32] reported lower prevalence of needle recapping. Better training and retraining of the HCWs may have contributed to the lower prevalence. Additionally, the class of HCWs involved in these studies may have contributed to that. Minority of the respondents $(9.0 \%)$ always bent needles after use. This shows a good practice as over $90.0 \%$ of the respondents do not bend needles after use. The finding in this study is similar to what was reported in a multistate study in Sothern Nigeria[22] where 7.9\% of the HCWs bent needles after use. Another Nigerian study also reported similar finding. [23] The finding is however higher than what was reported in a multi-centre study in Uganda where $2.7 \%$ of the respondents bent needles. The difference in proportion may be due to the class of HCWs involved in the study (doctors, nurses and laboratory technicians). This class of HCWs are known to have better knowledge and practice of SP.[27]Most of the HCWs always dispose used sharps immediately after use in sharp disposable boxes but a minor proportion that did not always engage in such practice still posed a danger to both themselves and the society. The finding in this study is similar to the report of other studies in Nigeria [22,23,35], Ethiopia[15] and Egypt.[25]

Less than half of the HCWs (48.0\%) reported Needle Stick and Sharp Injuries (NSSIs) by polluted sharps despite the presence of infectious disease control committee in the health facility. This strengthens the report that occupational NSSIs were generally under reported.[36]
This negates the $\mathrm{CDC}$ recommendation that all occupational accidents should be reported immediately so that PEP can be instituted within 2 hours of the accident.[37] The finding in this study is however similar to what was reported in another study in Nigeria.[38] This is however higher than what was reported in other studies in Nigeria,[36,39] and South East Ethiopia.[40] The poor reporting in these studies may be due to unavailability of good reporting system in their facilities.

A minor proportion of the HCWs $29.5 \%$ had good practice scores and this was lower than what was reported in similar studies.[23,35], although, contrastingly, another study reported a much lower practice score.[15] The result of the IDI showed poor practice of SP as majority of the HCWs graded the practice of SP poorly in their health facilities. This poor practice was linked mainly to unavailability of safety kits, emergency situations, many patients to attend to and inadequate hand washing facilities. A study on the availability of infection control supplies in health facilities in Nigeria reported poor availability of such supplies hence supporting the report of the HCWs in this study.[34] In the same study, only $84.0 \%$ of the respondents reported having hand washing facility in their departments.[34] Poor practice of SP due to emergency situations and many patients to attend to were mainly due to lack of adequate human resource prevalent in most developing countries.

\section{Conclusion}

The knowledge and practice of SP in this study were fair while the attitude was good but much improvement is still needed in order to achieve good knowledge and practice in this important aspect of hospital practice.

The government should provide enabling environment in form of infrastructures and necessary infection control materials for good practice of SP. Training and retraining of HCWs should be on regular basis.

\section{Limitation}

Social desirability bias may have occurred in the study as the HCWs may have reported socially acceptable responses rather than their actual day to day practice.

\section{Acknowledgments}

The authors acknowledge all the HCWs that participated in the study

\section{Conflict of Interest}

The authors declare no conflict of interest. 


\section{Funding}

The researchers did not receive any form of funding for the study.

\section{Availability of data and materials}

Materials and data will be available at the Department of Community Medicine, Enugu State University Teaching Hospital for a period of 5 years after the study.

\section{Authors' contributions}

The conception, design, drafting and interpretation of the research work, were done by HON while MA and CO analysed the data. All the authors critically revised the manuscript for final approval.

This article is published open access under the Creative Commons Attribution-NonCommercial NoDerivatives (CC BYNC-ND4.0). People can copy and redistribute the article only for non-commercial purposes and as long as they give appropriate credit to the authors. They cannot distribute any modified material obtained by remixing, transforming or building upon this article. See https:// creativecommons.org/licenses/by-nc-nd/4.0/

\section{References}

1. Abdulraheem IS, Amodu MO, Saka MJ, Bolarinwa OA, Uthman MMB. Knowledge, awareness and compliance with standard precautions among health workers in north eastearn Nigeria. J Community Med Heal Edu. 2012;2(3):1-5.

2. Bello AI, Asiedu En, Adegoke BOA, Quartery JNA, Appiah-Kubi KO, Owusu-Ansah B. nosocomial infections: Knowledge and source of information among clinical health care students in Ghana. Int J gen med. 2011;4:57174

3. Oguntona TS, Adedeji OO. Awareness and Use of Personnel Protective Equipment (PPE) and Practice of Safety Precautions Among Funeral Home Workers in Lagos State. Transnatl $J$ Sci Technol. 2012;2(9):47-53.

4. Omiepirisa YB. Universal precautions: A review. Niger Heal J. 2012;12(3):68-74.

5. CDC. Universal precautions for prevention of transmission of HIV and other blood borne infections. Fact sheet. www.cdc.gov [Accessed 29/6/2021].

6. Kalu FTU, Odusanya OO. Universal precautions: A study of knowledge and compliance amongst doctors in private medical practice in Lagos state, Nigeria. Niger J Gen Pract. 2012;10(2):4957.

7. CDC. Standard precautions, Excerpt from the guideline for isolations: preventing transmission of infectious agents in the health care settings . Centres for Disease Prevention and Control. 2007. Available at http://www. cdc.gov/ncidod/dhqp/gl isolation.
8. Cunrui H, Ma W, Stack S. The hygienic efficacy of different hand-drying methods: a review of the evidence. Mayo Clinic Proceedings. 2012; 87:8.

9. CDC.Guide to infection prevention for outpatient settings: minimum expectations for safe care. Centers for Disease Control and Prevention, National Center for Emerging and Zoonotic Infectious Diseases, Division of Healthcare Quality Promotion, 2011. Accessed 29/6/21

10.WHO. /Safe Injection Global Network (WHO/SIGN) Alliance. Available at www. who.int/injection safety/sign/en. [ Accessed 28/6/21].

11.CDC-Injection Safety. Available at www.cdc. gov/injectionsafety/index.html [Accessed 28/6/21].

12.FMOH J. Behaviour change communication strategy, Nigeria. FMOH and JSI/MMIS, Nigeria. June 2005: 5-22.

13.FMOH J. Training handout on injection safety in the context of infection prevention and control for health care personnel. FMOH and JSI/MMIS, Nigeria, 2006: 3-29.

14. Amoran O, Onwube O. Infection control and practice of standard precautions among healthcare workers in northern Nigeria. $J$ Glob Infect Dis. 2013;5(4):156.

15. Tariku GH, Eshetu HE, Abdella AA. Compliance with Standard Precautions and Associated Factors among Healthcare Workers in Gondar University Comprehensive Specialized Hospital, Northwest Ethiopia. J Environ Public Health. 2017. doi:10.1155/2017/2050635

16. Araoye M. Research Methodology with statistics for Health and Social Sciences. 1st ed. Nathadex; Ilorin; 2004. pg 120.

17. Arinze-Onyia S, Ndu A, Aguwa E, Modebe I, Nwamoh U. Knowledge and Practice of Standard Precautions by Health-Care Workers in a Tertiary Health Institution in Enugu, Nigeria. Niger $J$ Clin Pract. 2018;21(2):149-155.

18. Garner JS. Guideline for Isolation Precautions in Hospitals. The Hospital Infection Control Practices Advisory Committee. (HICPAC) for CDC. Infect Control Hosp Epidemiol. 1996; 17(1):53-80.

19. WHO guidelines on hand hygiene in health care: First global patient safety challenge clean care is safe care. Geneva, Switzerland: World Health Organization, 2010. Available at http://www.who.int/patientsafety/en/. [Accessed 29/6/21]. 
20.CDC. Guidance for the selection and use of personal protective equipment (PPE) in healthcare settings 2010. Available at https://www.cdc.gov>ppeslides. [Accessed 29/6/21]

21.Akazong EW, Tume C, Njouom R, Ayong L, Fondoh V, Kuiate J. knowledge, atitude and prevalence of hepatitis B virus among healthcareworkers:across-sectional, hospital based study in Bamenda health District, NWR, Cameroon. BMJ Open. 2020;10(3). doi: 10.1136/bmjopen-2019-031075

22. Ogoina D, Pondei K, Adetunji B, Chima G, Isichei C, Gidado S. Knowledge, attitude and practice of standard precautions of infection control by hospital workers in two tertiary hospitals in Nigeria. J Infect Prev. 2015/01/05. 2015;16(1):16-22.

23. Tobin EA, Asogun DA, Odia I, Ehidiamhen G. Knowledge and practice of infection control among health workers in a tertiary hospital in Edo State, Nigeria. Direct Res $J$ Heal Pharmacol. 2013;1(2):20-27.

24. Sreedharan J, Muttappillymyalil J, Venkotramana M. Knowledge about standard precautions among university hospital nurses in the United Arab Emirates. Eastern Mediterranean Health Journal. 2011; 17 (4), 331-334.

25. Eskander HG, Youssef W, Morsy M, Ali H, Elfeky A. Intensive Care Nurses ' Knowledge \& Practices regarding Infection Control Standard Precautions at a Selected Egyptian Cancer Hospital. Journal of Education and Practice. 2013;4(19):160-174.

26. Ahmad ER, Khamis M, Younis EM, Alrady SA. Effect of a Developed Educational Booklet about Standard Infection Control Precautions on Nurses' Knowledge and Practices at Women's Health Center-Assiut University Hospital, Egypt. Med J Cairo Univ. 2012;80(1):435-445.

27. Okechukwu EF, Motshedisi C. Knowledge and practice of standard precautions in public health facilities in Abuja, Nigeria. Int J Infect Control. 2012;8(3). doi:10.3396/ ijic.022.12

28.Agu PU, Ogboi SJ, Ezugwu EC, Okeke TC, Aniebue PN. The Knowledge, Attitude and Practice of Universal Precaution Among Rural Primary Health Care Workers In Enugu Southeast Nigeria. World $J$ Pharm and Pharmaceutical Sci. 2015;4(9):109-125.

29. Gebresilassie A, Kumei A, Yemane D. Standard precautions practice among health care workers in public health facilities of Mekelle special zone, Northern Ethiopia. $J$ Community Med Heal Educ. 2014;4(3):286.
30.Mpamize G. Adherence to Universal Precautions in Infection Prevention among Health Workers in Kabarole District. J Heal Med Nurs. 2016;26(2005):144-155.

31. Thu T, Anh N, Chau N, Hung N. Knowledge, Attitude and Practices regarding Standard and Isolation Precautions among Vietnamese Health Care Workers: a Multicenter CrossSectional Survey. Intern Med Open Access. 2012;2(4):1-5

32. Wasswa P, Nalwadda CK, Buregyeya E, Gitta SN, Anguzu P, Nuwaha F. Implementation of infection control in health facilities in Arua district, Uganda: a cross-sectional study. BMC Infect Dis. 2015;15(1):268.

33. Sethi AK, Acher CW, Kirenga B, Mead S, Donskey CJ KA. Infection Control Knowledge, Attitudes, and Practices among Healthcare Workers at Mulago Hospital, Kampala, Uganda. Infect Control Hosp Epidemiol. 2012;33(9):917-923.

34. Nwoga HO, Ajuba MO, Onwasigwe CN. Availability of infection control supplies in primary and tertiary government health facilities in Enugu Metropolis, Nigeria. Nigerian Research Journal of Clinical Sciences. 2019; 1\&2(9):43-52

35. Otovwe A, Adidatimi PO. Knowledge , Attitude and Practice of standard precaution among Health Care Workers in Federal Medical Centre Yenagoa. IOSR J Pharm Biol Sci. 2017;12(4):79-86.

36. Akeem BO, Abimbola A, Idowu AC. Needle stick injury pattern among health workers in primary health care facilities in Ilorin, Nigeria. Acad Res Int. 2011;1(3):419-427

37. CDC. Updated US Public Health Service guidelines for the management of occupational exposures to $\mathrm{HBV}, \mathrm{HCV}$, and HIV and recommendations for postexposure prophylaxis. MMWR Recomm Rep. 2001;50:152.

38. Amira CO, Awobusuyi JO. Needle-stick injury among health care workers in hemodialysis units in Nigeria: A multi-center study. Int $J$ Occup Environ Med. 2014;5(1):1-8.

39. Isara AR, Ofili AN. Prevalence of occupational accidents/Injuries among health care workers in a federal medical centre in southern Nigeria. West Afr J Med. 2012;31(1):47-51.

40. Bekele T, Gebremariam A, Kaso M, Ahmed K. Factors Associated with Occupational Needle Stick and Sharps Injuries among Hospital Healthcare Workers in Bale Zone, Southeast Ethiopia. PLoS One. 2015;10(10):e0140382. 